CORRECTION

https://doi.org/10.1038/s41586-019-1265-5

\title{
Author Correction: Design of amidobenzimidazole STING receptor agonists with systemic activity
}

Joshi M. Ramanjulu, G. Scott Pesiridis, Jingsong Yang, Nestor Concha, Robert Singhaus, Shu-Yun Zhang, Jean-Luc Tran, Patrick Moore, Stephanie Lehmann, H. Christian Eberl, Marcel Muelbaier, Jessica L. Schneck, Jim Clemens, Michael Adam, John Mehlmann, Joseph Romano, Angel Morales, James Kang, Lara Leister, Todd L. Graybill, Adam K. Charnley, Guosen Ye, Neysa Nevins, Kamelia Behnia, Amaya I. Wolf, Viera Kasparcova, Kelvin Nurse, Liping Wang, Ana C. Puhl, Yue Li, Michael Klein, Christopher B. Hopson, Jeffrey Guss, Marcus Bantscheff, Giovanna Bergamini, Michael A. Reilly, Yiqian Lian, Kevin J. Duffy, Jerry Adams, Kevin P. Foley, Peter J. Gough, Robert W. Marquis, James Smothers, Axel Hoos \& John Bertin

Correction to Nature https://doi.org/10.1038/s41586-018-0705-y, published online 07 November 2018.

In this Letter, author Ana C. Puhl was inadvertently omitted from the list of authors, with affiliation: Platform Technology \& Science, GlaxoSmithKline, Collegeville, PA, USA. At the time this research was initiated, Ana C. Puhl held a post-doctoral position at GlaxoSmithKline through a fellowship awarded from the Brazilian government (the 'Science without Borders' programme), and the GlaxoSmithKline 'Trust in Science' programme. She performed crystallization trials and was instrumental in the determination of the structure of compounds 1 and $\mathbf{2}$ described in Figs. 1 and 2. In the 'Author contributions' section, the relevant sentence should read: "N.C. performed HDX studies and determined X-ray structures with assistance from L.W. and A.C.P.”. The Letter has been corrected online. 